\title{
Influence of pulsed DC current and electric field on growth of carbide ceramics during spark plasma sintering
}

\author{
Takayuki KONDO, Taku KURAMOTO, Yasuhiro KODERA, Manshi OHYANAGI and Zuhair A. MUNIR*
}

Department of Materials Chemistry, Innovation Materials and Research Center, Ryukoku University, Otsu-shi Shiga, 520-2194

*Department of Chemical Engineering and Materials Science, University of California, Davis, CA 95616, USA

\begin{abstract}
The influence of the pulsed DC current and the electric field on the growth of TiC and ZrC layers using Spark Plasma Sintering was investigated at temperature ranging from 1373 to $1823 \mathrm{~K}$. From the results of XRD and EDS analyses, the product layer formed between $\mathrm{Ti}$ and $\mathrm{C}$ was only $\mathrm{TiC}$, and the layer between $\mathrm{Zr}$ and $\mathrm{C}$ was only $\mathrm{ZrC}$. In all systems, the thickness and the growth rate constant of the product layers were enhanced in the system with the current compared to that in the system with the negligible current. The activation energy for the TiC layer growth was calculated to be $269 \pm 3 \mathrm{~kJ} / \mathrm{mol}$ in the system with the current, which is smaller than the activation energy of $273 \pm 2 \mathrm{~kJ} / \mathrm{mol}$ in the system with the negligible current. In the $\mathrm{Zr}-\mathrm{C}$ system, these values were $205 \pm 7 \mathrm{~kJ} / \mathrm{mol}$ and $224 \pm 1 \mathrm{~kJ} / \mathrm{mol}$, respectively. The increase in the growth of the TiC and $\mathrm{ZrC}$ layers was unaffected by the current direction and suggested that the increased point defect mobility by passing the current was a dominant cause of the enhanced growth.
\end{abstract}

(C)2008 The Ceramic Society of Japan. All rights reserved.

Key-words: Pulsed DC current, Electric field, Spark plasma sintering, Electromigration, Diffusion couple

[Received June 2, 2008; Accepted September 11, 2008]

\section{Introduction}

The Spark Plasma Sintering (SPS) technique makes it possible to consolidate metals and ceramics powers at relatively low temperature and in a short period. It is widely investigated and utilized in the fabrication of functionally graded materials, intermetallic compounds, metal matrix composites, and nanocrystalline materials. ${ }^{1,2)}$ The sinterability of powder in the SPS technique is presumably accelerated due to low-voltage and high-intensity current that can be directly applied to the specimen through a graphite die with external pressure in the technique. ${ }^{3)}$ However, scant direct evidence exists for the acceleration mechanism, and the role of the current remains unclear.

Recently, to clarify the role of the current in SPS, the effect of the current on diffusion kinetics in the diffusion couple of MoSi was investigated by an SPS apparatus. ${ }^{4), 5}$ The growth rate of the product phase formed between Mo and Si showed a strong dependence on the current in the SPS. ${ }^{6}$ These phenomena suggest that atomic diffusion in the specimen is accelerated due to the point defect, and defect mobility increased by passing the current in the layers. In other words, the applied current can provide an added driving force to the chemical potential for atomic diffusion. The electrical force (electromigration) proposed by Huntington and Grone is taken to be

$$
F_{\mathrm{em}}=Z^{*} e E=\left(Z_{\mathrm{el}}^{*}+Z_{\mathrm{wd}}^{*}\right) e E
$$

where $e$ is the charge of an electron, $E$ is the electric field ( $E=$ $\rho \mathrm{j}, \rho$ is resistivity, and $\mathrm{j}$ is current density), and $Z^{*}$ is the intrinsic effective valence of the specimen. $Z_{\mathrm{el}}{ }^{*} e E$ is called the direct force, and $Z_{\mathrm{wd}}{ }^{*} e E$ is called the electron wind force. ${ }^{6)}$ Furthermore, the acceleration of atomic diffusion is asymmetric due to the electron wind force caused by electron movement from the cathode to the anode. Indeed, the influence of the current direction on atomic diffusion in the $\mathrm{Sn}-\mathrm{Ni}$ reaction couple was investigated under an applied current of approximately $500 \mathrm{~A} / \mathrm{cm}^{2}$, and the thickness of the product layers formed between the SnNi reaction couple was changed by the direction of the current. ${ }^{7)}$ Due to this result, the signs of the effective valance of the Sn solid-dissolved in $\mathrm{Ni}$ and the $\mathrm{Ni}$ solid-dissolved in Sn are negative in the presence of the current, but since the absolute values of each effective valance are different, the thicknesses of the product layers were different by the influence of the electric field. Similar results were also observed for the $\mathrm{Sn}-\mathrm{Ag}$ and $\mathrm{Sn}-$ $\mathrm{Cu}$ reaction couples. ${ }^{8,9)}$ In the case of the formation of solid solution, the effect of the current on the interdiffusivity in the $\mathrm{Cu}-\mathrm{Ni}$ system was investigated over a temperature range of $923-1123 \mathrm{~K}$ and at current values in the range of $0-1000 \mathrm{~A}^{10}{ }^{10}$ When the electronic flow was from $\mathrm{Ni}$ to $\mathrm{Cu}$, interdiffusivity showed a marked increase relative to copper content, but it was unchanged when the electronic flow was from $\mathrm{Cu}$ to $\mathrm{Ni}$. The sign of effective valance for $\mathrm{Ni}$ and $\mathrm{Cu}$ self-diffusion are both negative. The diffusion mechanism resembles solid solution as in self-diffusion. It can be assumed that an electron wind in the $\mathrm{Cu}-\mathrm{Ni}$ solid solution would also cause the atoms to move preferentially toward the electron. Therefore, the role of the current has been determined in metals and intermetallic compounds with a metallic bond. However, the influence of the current and the electric field on diffusion (mass transfer) has barely been investigated in cases of electrically conductive ceramics with a comparatively strong covalent bond even though SPS can consolidate carbide ceramics with a high melting point at a lower sintering temperature for a shorter holding time. In this work, we used the different sign of the effective valance (the sign of the effective valance of the $\mathrm{C}$ solid-dissolved in $\mathrm{Ti}$ is positive ${ }^{11)}$ and the sign of the $\mathrm{C}$ solid-dissolved in $\mathrm{Zr}$ is negative ${ }^{11)}$ under the influence of the electric field) and investigated the influence of the pulsed DC current and the electric field on the growth of $\mathrm{TiC}$ and $\mathrm{ZrC}$ layers using SPS at temperature ranging from 1373 to $1823 \mathrm{~K}$. 


\section{Experimental procedure}

Square Ti (99.9\% purity obtained from Nilako Co., Ltd., Japan), Zr (99.9\% purity obtained from Nilako Co., Ltd., Japan) plates $0.1 \mathrm{~mm}$ thick, and C (purity of $>98 \%$ obtained from SGL CARBON Co., Ltd., Germany) plates $1.0 \mathrm{~mm}$ thick were used in the preparation of the diffusion couple. The dimensions of all $\mathrm{Ti}, \mathrm{Zr}$, and C plates were $10 \mathrm{~mm}$. The samples consisted of three layers with a single $\mathrm{Me}(\mathrm{Me} ; \mathrm{Ti}, \mathrm{Zr})$ plate sandwiched between two $\mathrm{C}$ plates. The three-layer assembly provides both a $\mathrm{C}-\mathrm{Me}$ and a $\mathrm{Me}-\mathrm{C}$ interface to investigate the influence of current direction on atomic diffusion. Before assembling each sample, the $\mathrm{Me}$ and $\mathrm{C}$ plates were polished with 2000 -grit $\mathrm{SiC}$ abrasive paper, rinsed in distilled water, and ultrasonically cleaned by acetone.

All experiments were carried out in the SPS apparatus (Model 1050, Sumitomo Coal and Mining Co.). The pulsed cycle of the DC current was 12:2, i.e., 12 pulses of $3 \mathrm{~ms}$ on and 2 pulses of $3 \mathrm{~ms}$ off. Figure 1 shows the SPS apparatus and the local setting around the sample: (a) with the current and (b) with the extremely low current compared to the current passing through the carbon plate and die, that is, the negligible current. So that the current only passes through the specimen, the graphite die was not used in the presence of the current, as shown in Fig. 1(a). In the system with the negligible current, an additional layer as an insulator (silicon carbide with boron and carbon: $\mathrm{SiC}+\mathrm{B}+$ C-disk: $3 \mathrm{~mm}, \varphi: 20 \mathrm{~mm}$ ) was placed on the top and the bottom of the sample to ensure that the current only passes through the graphite die, not the specimen, as shown in Fig. 1(b). The SPS program (annealing temperature: $1373-1823 \mathrm{~K}$, heating rate: 100 $\mathrm{K} / \mathrm{min}$, annealing time: $180-1800 \mathrm{~s}$ ) was set, and the temperature of the diffusion couple during SPS was measured and controlled by an optical pyrometer focused on the center of the specimen coated by graphite powders. Simultaneously, the sample temperature was also measured by a C-type thermocouple (W-5\% Re, $\mathrm{W}-26 \% \mathrm{Re}$ ) inserted through a hole drilled in the side of the graphite disk (distance between sample and thermocouple was approximately $1 \mathrm{~mm}$ ), as shown in Figs. 1(a) and (b). In all experiments, pressure of $10 \mathrm{MPa}$ was applied to ensure good electrical contact in the whole system. All samples were heattreated using SPS under vacuum conditions less than 5.0 Pa and cooled to room temperature by turning off the power.

To observe the product layer formed between the Me and $\mathrm{C}$ layers, all samples prepared by SPS were sectioned and mounted in conductive epoxy resin. Then 3000-grit $\mathrm{SiC}$ abrasive paper
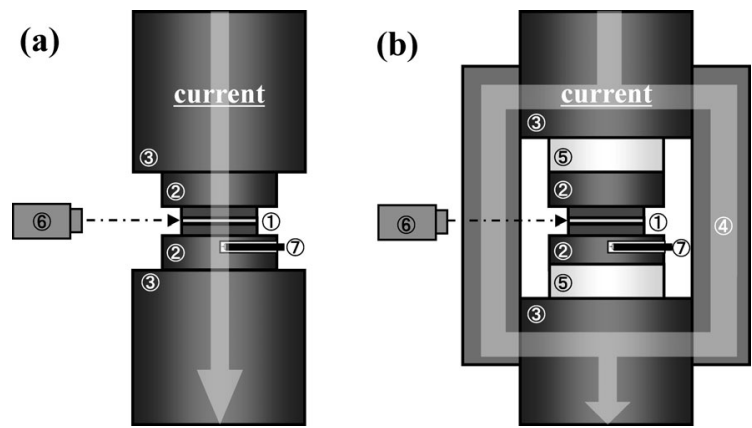

Fig. 1. Schematic of the Me-C (Me: Ti, Zr) diffusion couple (a) with the current and (b) with the extremely low current. 1: Me-C diffusion couple, 2: Graphite disk, 3: Graphite plunger, 4: Graphite die, 5: Insulator $(\mathrm{SiC}+\mathrm{B}, \mathrm{C}), 6$ : Optical pyrometer, 7: Thermocouple. and $1-\mu \mathrm{m}$ diamond paste were used to polish the specimens. Consecutively, all samples were rinsed in distilled water and ultrasonically cleaned by acetone. The layer thickness was measured from back-scattered electron images (BEI) taken by scanning electron microscopy equipped with energy dispersive X-ray spectroscopy (EDS) (JSM-5410, JEOL, Tokyo Japan) to calculate the growth rate constant of the product layer and the activation energy for its formation. X-ray diffraction (RINT2500, $\mathrm{Cu} \mathrm{K} \alpha$ radiation operated at $100 \mathrm{~mA}$ and $40 \mathrm{kV}$, RIGAKU Co., Tokyo) was used as an identification method of the product phase.

\section{Results and discussion}

\subsection{Temperature measurement of specimen in SPS}

In the investigation the growth rate constant and the activation energy for the formation of product layer, the temperature of the specimen is crucial and requires an accurate temperature measurement method. In order to measure the sample temperature, two different methods (optical pyrometer and C-type thermocouple) were carried out in this work. The optical pyrometer that focused on the center of the sample, and a C-type thermocouple that focused on the bottom of the sample were utilized to compare the temperature between the center and the bottom of the sample. Figure 2 shows that there is only a slight temperature difference between the optical pyrometer and the thermocouple while the temperature is rising in the SPS. However, since the thermocouple did not touch the sample placed on the graphite plunger, as shown in Figs. 1(a) and (b), the temperature difference between the optical pyrometer and the thermocouple was approximately $10 \mathrm{~K}$. Hence, in this work, the temperature measured by the optical pyrometer was used as the temperature of the sample.

\subsection{Identification of product phase}

Figures 3(a) and (b) show the BEI micrographs of the product layers formed between $\mathrm{Ti}$ and $\mathrm{C}$ at $1518 \mathrm{~K}$ for $1800 \mathrm{~s}$ in the system with the current and the negligible current, respectively. A different contrast was clearly found, as in Figs. 3(a) and (b). Thus, XRD measurement was carried out to identify the product phase. Figures 4(a) and (b) show the XRD patterns of the product layer annealed at $1518 \mathrm{~K}$ for $1800 \mathrm{~s}$ in the system with the

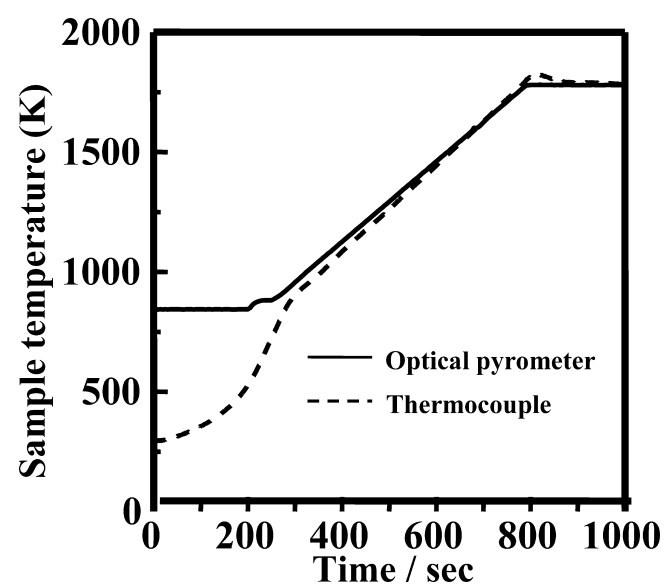

Fig. 2. Comparison between optical pyrometer and C-type thermocouple at various temperature in $\mathrm{Ti}-\mathrm{C}$ diffusion couple during temperature rising. 

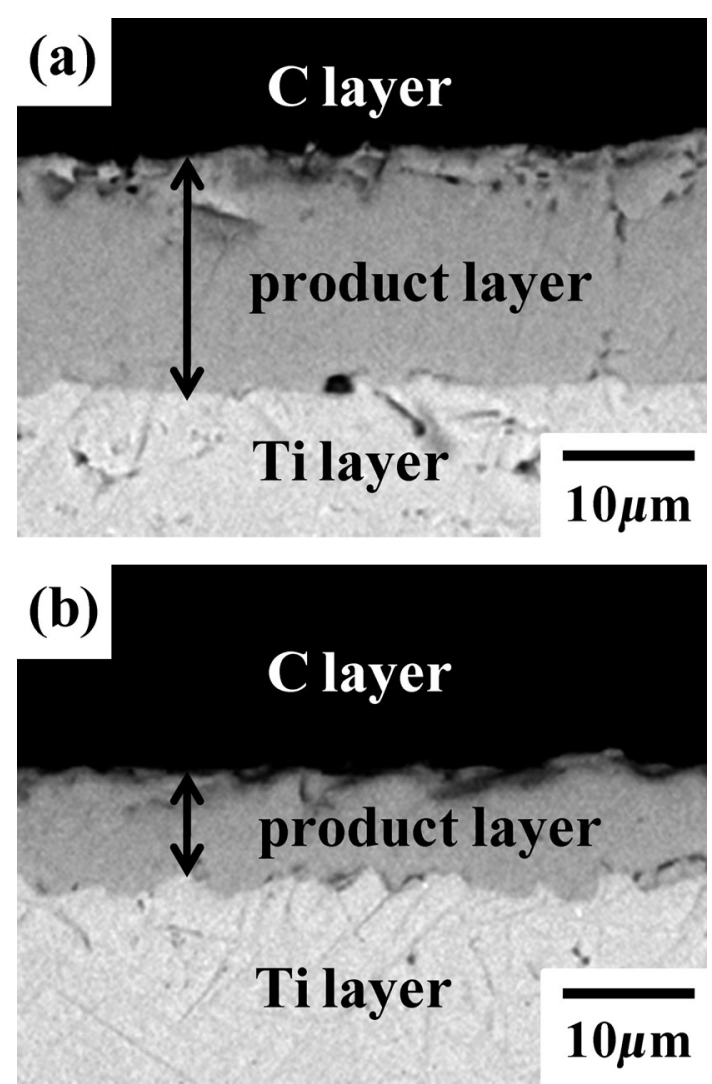

Fig. 3. Back scattered electron image (BEI) of the produced layer of the reaction between $\mathrm{Ti}$ and $\mathrm{C}$ at $1518 \mathrm{~K} 1800 \mathrm{~s}$ (a) with the current and (b) with the negligible current.

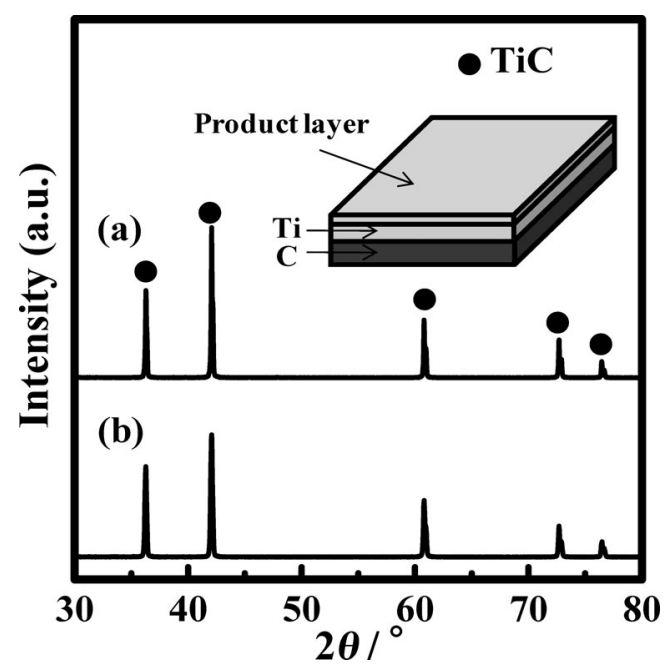

Fig. 4. XRD pattern of Ti-C diffusion couple annealed at $1518 \mathrm{~K}$ for $1800 \mathrm{~s}$ (a) with current and (b) with the negligible current.

current and the negligible current. Regardless of the presence of the current, annealing time, and temperature, the product phase formed between $\mathrm{Ti}$ and $\mathrm{C}$ was only $\mathrm{TiC}$. Similar results were also obtained from the $\mathrm{Zr}-\mathrm{C}$ system; Figs. 5(a) and (b) show the BEI micrographs of the product layers formed between $\mathrm{Zr}$ and $\mathrm{C}$ at $1773 \mathrm{~K}$ for $1800 \mathrm{~s}$ in the system with the current and the negligible current, respectively. XRD measurement was carried out to identify the product phase due to the different contrast that was
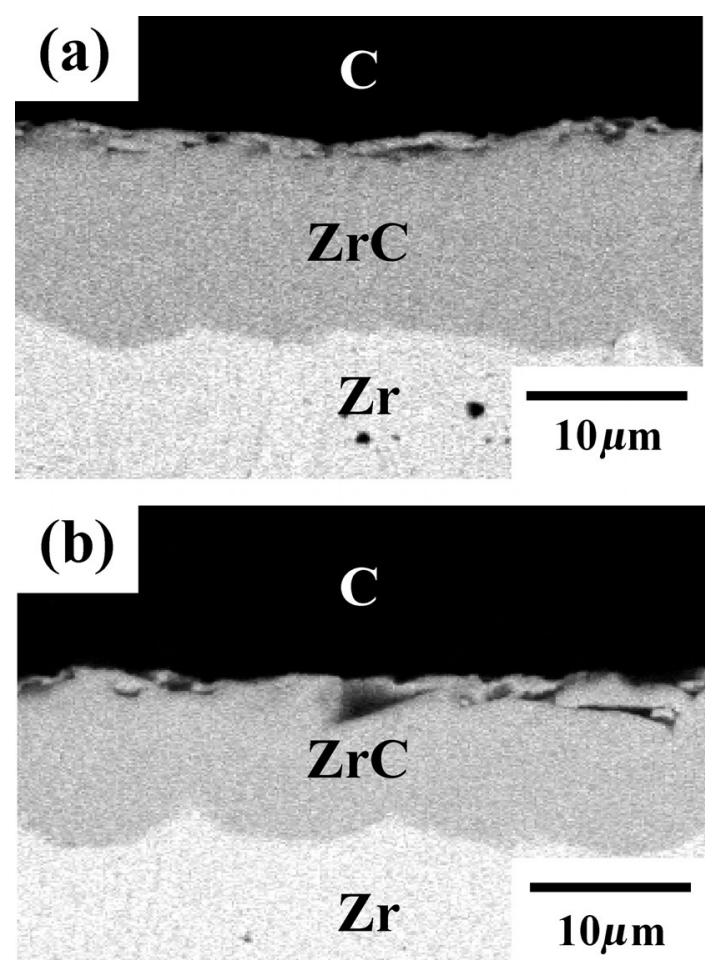

Fig. 5. BEI of the product layer of the reaction between $\mathrm{Zr}$ and $\mathrm{C}$ at $1773 \mathrm{~K} 1800 \mathrm{~s}$ (a) with current and (b) with the negligible current.

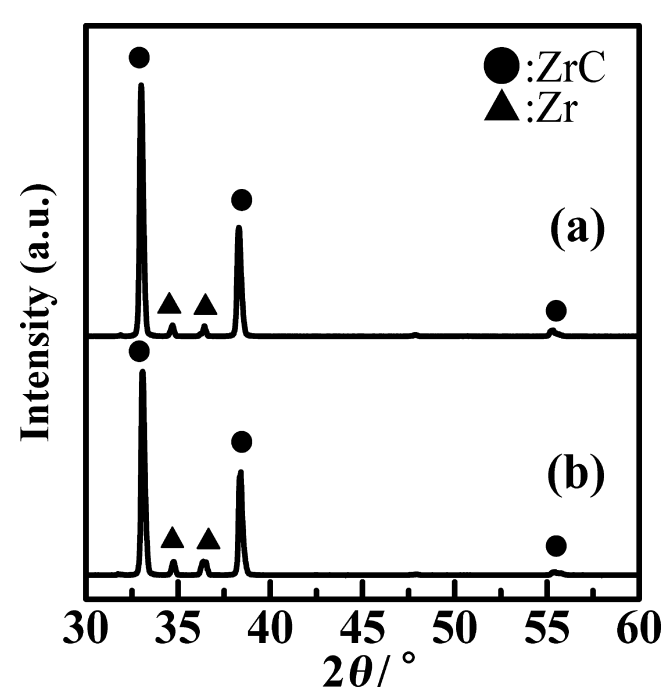

Fig. 6. XRD patterns of $\mathrm{Zr}-\mathrm{C}$ diffusion couple annealed at $1773 \mathrm{~K}$ for $1800 \mathrm{~s}$ (a) with the current and (b) with the negligible current.

clearly found. Figures 6(a) and (b) show the XRD patterns of the product layer annealed at $1773 \mathrm{~K}$ for $1800 \mathrm{~s}$ in the system with the current and the negligible current. From the XRD results, the product phase formed between $\mathrm{Zr}$ and $\mathrm{C}$ was only $\mathrm{ZrC}$. The composition of the phase corresponded with the Ti-C and $\mathrm{ZrC}$ phase diagrams.

3.3 Influence of current direction on product layer thickness

In all experimental conditions, the growth of the product layers, which paralleled the interfaces between the Me (Me; Ti, 
Zr) and C plates, was observed. The thickness of the product layers was measured by BEI. The product layer thicknesses formed between $\mathrm{Ti}$ and $\mathrm{C}$ at $1518 \mathrm{~K}$ for $1800 \mathrm{~s}$ in the system with the current and the negligible current were approximately 17 and 10 $\mu \mathrm{m}$, respectively, and those formed between $\mathrm{Zr}$ and $\mathrm{C}$ at $1518 \mathrm{~K}$ for $1800 \mathrm{~s}$ in system with the current and the negligible current were approximately 15 and $10 \mu \mathrm{m}$, respectively. In both cases, the voltage (electric field) applied to the sample was approximately $6 \mathrm{~V}$. Regardless of annealing time and temperature, the product layers annealed in the presence of current were constantly much thicker than those in the system with the negligible current. The enhancement of product layer thickness was only clearly observed in the system with the current. Moreover, to investigate the current direction on the product layer thickness during SPS, we carried out two different systems (with the current and with the negligible current). With the current, the graphite die was not used so that the current only went through the sample. On the other hand, in the system with the negligible current, an additional layer as insulator was placed on the top and bottom of the sample to make the current go through the graphite die, not the sample. Figures 7(a) and (b) show the influence of the current direction on the product layer thickness, as measured at the two $\mathrm{Me}-\mathrm{C}$ interfaces in the Me-C diffusion couple. However, the thickness of the product layer was independent of the current direction, as seen in Figs. 7(a) and (b). This result agrees with recent observations on the growth of intermetallic layers in the system with current. ${ }^{4), 5), 12-14)}$ If the acceleration of atomic diffusion in the presence of current is dominantly caused by the electron wind force, the bottom layer thickness in the Me-C diffusion couple must be higher than the top layer thickness due to the electron transfer from the bottom to the top electrodes in SPS. In contrast, the direct force depends on the intrinsic effective valence of the specimen. The sign of the effective valance of the $\mathrm{C}$ solid-dissolved in $\mathrm{Ti}$ is positive in the presence of the current, and that of the $\mathrm{C}$ solid-dissolved in $\mathrm{Zr}$ is negative in the presence of the current. ${ }^{11)}$ In other words, the direction of the diffusion of $\mathrm{C}$ dissolved in $\mathrm{Ti}$ under the presence of the current is the opposite of the direction of the electron by the influence of the electric field. In the $\mathrm{Zr}-\mathrm{C}$ system, the direction is the same as the electron. However, in this work, the difference between the bottom and top layer thicknesses was negligible, which usually results in the intricate diffusion of $\mathrm{C}$ and Me while maintaining the structures of each compound of $\mathrm{TiC}$ and $\mathrm{ZrC}$. Therefore, mass transfer in the SPS system was independent of the intrinsic effective valence of the specimen. According to Munir et al., the current plays a role in increasing the point defect and enhancing the defect mobility. ${ }^{15)}$ Thus, we considered that the current did not influence the direction of the growth of the product layer, but the presence of high dense current enhanced the point defects and the defect mobility in the layers.

\subsection{Influence of pulsed DC current on the growth of product layer}

The effect of the current on the growth rate constant of TiC and $\mathrm{ZrC}$ was investigated by varying the annealing time and temperature. In both cases of the system with the current and the negligible current, the product layer thickness increased with annealing time and temperature. To calculate the growth rate constant, we used Eq. (2):

$$
x^{2}=k t
$$

where $x^{2}$ is the square of the product layer thickness, $k$ is the growth rate constant, and $t$ is the annealing time.

Figures 8(a) and (b) show the growth rate constant of $\mathrm{TiC}$ and $\mathrm{ZrC}$ layers in the system with the current and the negligible current. In both the $\mathrm{Ti}-\mathrm{C}$ and $\mathrm{Zr}-\mathrm{C}$ systems, the growth rate constant of $\mathrm{TiC}$ and $\mathrm{ZrC}$ increased with annealing temperature. A considerable increase in the growth rate constant under the system with the current is observed compared to the system with the negligible current. For the Ti-C system, the current density through the sample was approximately $820 \mathrm{~A} / \mathrm{cm}^{2}$, and in the $\mathrm{Zr}-\mathrm{C}$ system it was approximately $750 \mathrm{~A} / \mathrm{cm}^{2}$. The growth rate of the product layers was accelerated by passing the current through the sample, and mass transfer clearly showed a dependence on the current in the $\mathrm{Me}-\mathrm{C}$ systems.

To calculate the activation energy for the formation of the product layer, we used an Arrhenius Eq. (3):

$$
\ln k=\ln A-\left(\frac{E a}{R T}\right)
$$

where $E a$ is the activation energy for the formation of the product layer, $k$ is the growth rate constant, $A$ is the constant, $R$ is the gas constant, and $T$ is the annealing temperature. The temperature dependence of the growth rate constant is shown in Figs. 9(a) and (b). The activation energy of $269 \pm 3 \mathrm{~kJ} / \mathrm{mol}$ was calculated to form the product layer in the system with the current. On the other hand, in the system with the negligible current, the activation energy was calculated to be $273 \pm 2 \mathrm{~kJ} / \mathrm{mol}$, a similar value
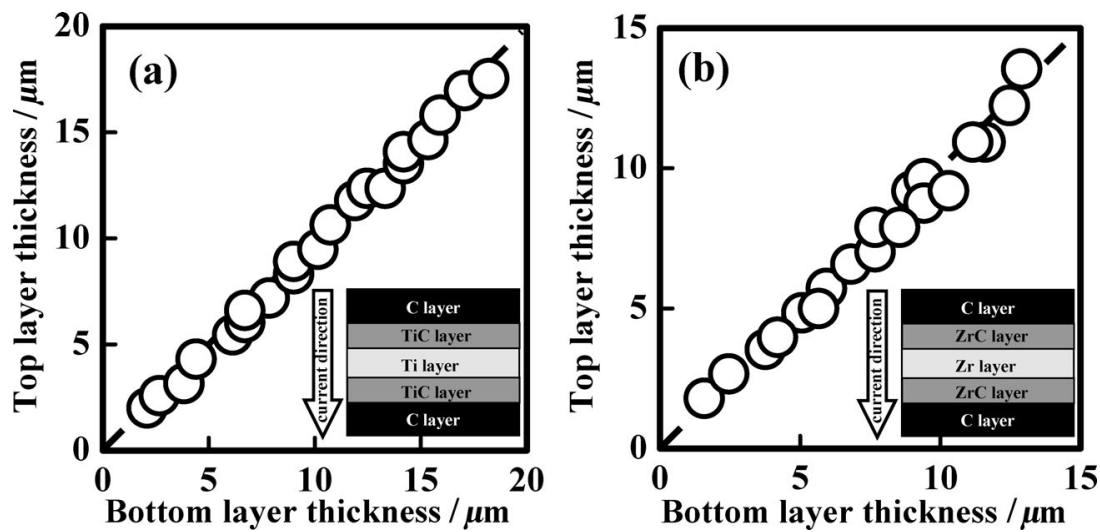

Fig. 7. (a) Comparison between TiC layer thickness at the two (Ti-C and C-Ti) interface to the direction of the current. (b) Comparison between $\mathrm{ZrC}$ layer thickness at the two $(\mathrm{Zr}-\mathrm{C}$ and $\mathrm{C}-\mathrm{Zr})$ interface to the direction of the current. 

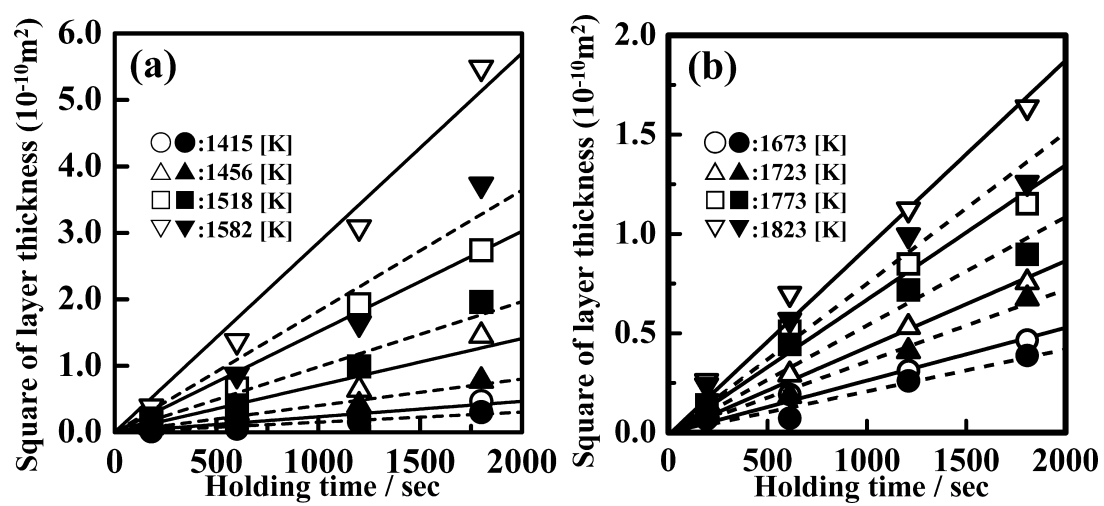

Fig. 8. Product layer thickness vs. time for $\mathrm{Me}-\mathrm{C}$ diffusion couple ((a) $\mathrm{Ti}-\mathrm{C}$, (b) $\mathrm{Zr}-\mathrm{C}$ ) annealed at various temperature with the current (opened dot) and with the negligible current (closed dot).
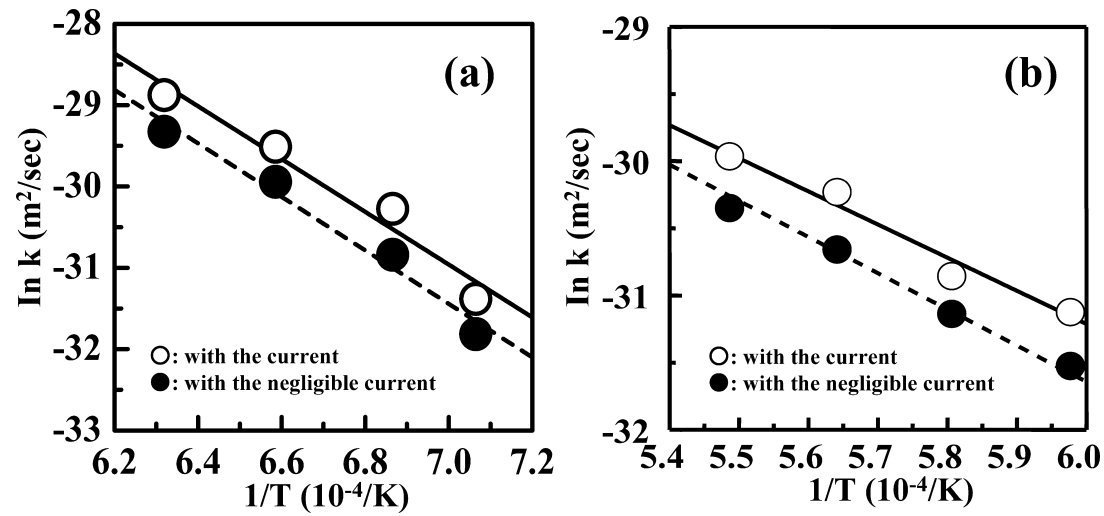

Fig. 9. Arrhenius plot of the temperature dependence in the system with the current and the negligible current flowing through the sample (a) $\mathrm{TiC}$ and (b) $\mathrm{ZrC}$.

compared with activation energy in the system with the current that agreed with literature reports in the system with the negligible current. ${ }^{16)}$ Also, in the system with the current, the activation energy for the formation of $\mathrm{ZrC}$ was calculated to be 205 $\pm 7 \mathrm{~kJ} / \mathrm{mol}$, and in the system with the negligible current, it was calculated to be $224 \pm 1 \mathrm{~kJ} / \mathrm{mol}$ for the formation of $\mathrm{ZrC}$. A significant difference in activation energy was not observed in the two cases, as seen from Figs. 9(a) and (b). These results are in good agreement with Anselmi-Tamburini et al., ${ }^{4)}$ who investigated the effect of electromigration in a Mo-Si diffusion couple during SPS in which a difference of activation energy for the formation of the product layer in the system with the current and the negligible current was not observed. Moreover, activation energy or the formation of intermetallic compounds did not practically change with current density even though it indicated that the growth rate constant significantly increased with current density. ${ }^{12)}$ These results suggest that the current helps increase the point defect and enhances the defect mobility in the layers.

Recently, Asoka-Kumar et al. provided direct evidence for an increase in vacancy concentration as a result of applied current. ${ }^{17)}$ They found that with a current density of $8.0 \times 10^{4} \mathrm{~A} / \mathrm{cm}^{2}$ utilizing positron annihilation spectroscopy, vacancy concentration in $\mathrm{Al}-\mathrm{Cu}$ was clearly increased compared to that in the system with the negligible current. Furthermore, a more recent positron annihilation investigation on $\mathrm{Ni}_{3} \mathrm{Ti}$ indicated that enhanced mobility is the primary effect of the current. ${ }^{15)}$ Also, high dense current in metals increases the point defect due to momentum transfer from high energy electrons to metal ion. $\left.{ }^{6}\right)$ That is, high current enhances the mobility of the generated point defect. Hence, the growth of the product layers of $\mathrm{TiC}$ and $\mathrm{ZrC}$ increased in the presence of current as a result of enhanced defect mobility and concentration of the point defect.

\section{Conclusion}

The influence of the current on the growth of $\mathrm{TiC}$ and $\mathrm{ZrC}$ layers using SPS was investigated at temperature ranging from 1373 to $1823 \mathrm{~K}$. From the results of XRD and EDS analyses, the product layer formed between $\mathrm{Ti}$ and $\mathrm{C}$ was only $\mathrm{TiC}$, and that formed between $\mathrm{Zr}$ and $\mathrm{C}$ was also only $\mathrm{ZrC}$, respectively. In all systems, the thickness and the growth rate constant of the product layers were enhanced in the system with the current compared to that in the system with the negligible current. The activation energy for the growth of $\mathrm{TiC}$ layer was calculated to be $269 \pm 3 \mathrm{~kJ} / \mathrm{mol}$ in the system with the current, which was smaller than the activation energy of $273 \pm 2 \mathrm{~kJ} / \mathrm{mol}$ in the system with the negligible current. In the $\mathrm{Zr}-\mathrm{C}$ system, these values were $205 \pm 7 \mathrm{~kJ} / \mathrm{mol}$ and $224 \pm 1 \mathrm{~kJ} / \mathrm{mol}$, respectively. The increase in the growth of the $\mathrm{TiC}$ and $\mathrm{ZrC}$ layers was unaffected by the direction of the current, implying that electromigration was a dominant cause of the enhanced growth. The growth of the product layers is accelerated due to the enhancement of point defects and defect mobility in the metal layer in the presence of high dense current. 


\section{References}

1) Z. A. Munir, U. Anselml-Tamburini and M. Ohyanagi, $J$. Mater. Sci., 41, 763-777 (2006).

2) M. Omori, Mater. Sci. Eng. A, 287, 183-188 (2000).

3) Z. Shen, M. Johnsson, Z. Zhao and M. Nygren, J. Am. Ceram. Soc., 85[8], 1921-1927 (2002).

4) W. Chen et al., Mater. Sci. Eng. A, 394, 132-138 (2005).

5) U. Anselmi-Tamburini, J. E. Garay and Z. A. Munir, Mater. Sci. Eng. A, 407, 24-30 (2005).

6) H. B. Huntington and A. R. Grone, J. Chem. Soli., 20[1/2], 7687 (1961).

7) C. M. Chen and S. W. Chen, J. Electron Mater., 28[7], 902906 (1999).

8) S. W. Chen, C. M. Chen and W. C. Liu, J. Electron Mater., 27[11], 1193-1198 (1998).

9) M. Y. Du, C. M. Chen and S. W. Chen, Mater. Chem. Phys., $82,818-825$ (2003).
10) J. Zhao, J. E. Garay, U. Anselmi-Tamburini and Z. A. Munir, J. Appl. Phys., 102, 114902-114907 (2007).

11) F. A. Schmidt and O. N. Carlson, Met. Trans. A, 7A, 127-132 (1976).

12) J. R. Friedman, J. E. Garay, U. Anselmi-Tamburini and Z. A. Munir, Intermetallics, 12, 589-597 (2004).

13) N. Berrolino, J. Garay, U. Anselmi-Tamburini and Z. A. Munir, Scripta Mater., 44, 737-742 (2001).

14) J. E. Garay, U. Anselmi-Tamburini and Z. A. Munir, Acta Mater., 51, 4487-4495 (2003).

15) J. E. Garay, S. C. Glade and U. Anselmi-Tamburini, App. Phys. Lett., 85, 573-575 (2004).

16) D. L. Kohlstedt, W. S. Williams and J. B. Woodhouse, J. Appl. Phys., 41, 4476-4484 (1970).

17) P. Asoka-Kumar, P. J. Simpson and K. P. Rodbell, App. Phys. Lett., 68, 406-408 (1996). 